\title{
Editorial
}

\section{Back to the Future of Rheumatology}

The medical cycle of discovery from researcher to editor to reviewer to publisher to researcher and back again - often re-engaging the same players in different roles - is a model for vetting and sharing medical information that inspired longtime Journal Editor Duncan Gordon ${ }^{1}$ (Figure 1).

Little did anyone know at that time - not Duncan Gordon, the associate editors, reviewers, and authors - to what extent the discovery process would speed up and multiply itself, in particular with the emergence of electronic resource networks on the Internet.

Today, electronic resources are apparent at every stage of the discovery process from submission to post publication. Following on implementation of the DOI to assign a unique digital content identifier to each published report came the ORCID, a unique digital identifier for authors, which is now a registration option when submitting manuscripts to The Journal; and when publicly funded authors submit a manuscript to The Journal, they can select from the names of funders in the Fundref database, another digital "authority." As a Select Deposit publisher, The Journal exports manuscripts on behalf of publicly funded authors who are required to deposit to PubMed Central or European PubMed Central. Implementing identification "authorities" promotes unambiguous, accurate identification and attribution to ensure continued discoverability in a global information environment that has become increasingly complex. Regarding attribution to multicenter studies where data are provided by non-author contributors, their metadata are now included in the metadata exported to PubMed and indexed on Medline.

On the distribution side, The Journal of Rheumatology has already seen 2 generations of electronic publishing: First, The Journal's inhouse-published online edition from

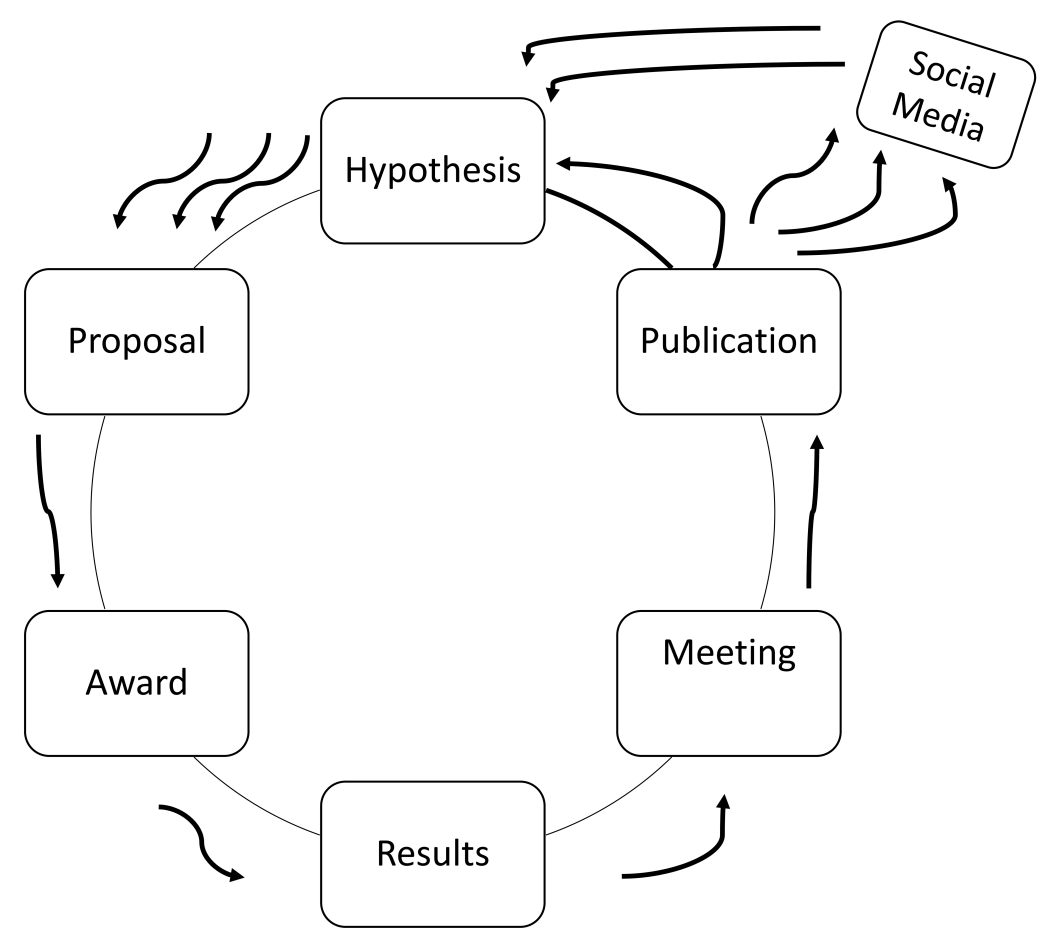

Figure 1 . The medical discovery cycle; adapted with permission ${ }^{1}$. 
2001-2008, followed in 2009 by a move to the HighWire Press hosting platform, with improved discovery features, including full-text access to other HighWire platform journals through interjournal citation linking.

Fast forwarding to 2017, The Journal begins Volume 44 - our 16th published electronically - with a relaunch of our online edition featuring a new responsive design layer, Drupal J-Core. Viewers will find more features at the article level such as article-level metrics, which encourage discovery. As well, viewers will note a redesigned logo cover and table of contents for both the print and online editions. The new features and format of the Website are part of a standard J-Core module, but the shaping and choice of features were inspired by Duncan Gordon's vision of facilitating discovery and fostering engagement and interaction. Here is a list of some of the main features:

- Custom collections on timely topics

- Rheumatology forum for residents and physicians

- The most-read articles

- Single article metrics

- Integrated social media for sharing

- Suggested articles based on reader preferences

- PowerPoint format for figures, tables

- E-letters for editor and reader comment

- Streamlined access to publisher services

There are a number of additional features that also serve to engage the viewer and facilitate wider exploration of research topics. We invite you to circle back to our home page jrheum.org and start with the Editor's Picks. Your comments and suggestions are welcome. You can reach us through the Feedback page.

YVONNE H. PIGOTT,

Managing Editor;

CARLYLE M. RODRIGO,

Manuscript Manager;

EARL D. SILVERMAN, MD,

Editor-in-Chief,

The Journal of Rheumatology

Address reprint requests to Dr. E.D. Silverman; e-mail: jrheum@jrheum.com

\section{REFERENCE}

1. Gordon DA. The medical discovery cycle. Tokyo: Churchill-Livingston; 1992:457-60.

J Rheumatol 2017;44:140-1; doi:10.3899/jrheum.161558 